\title{
A Review: ETL-As a Tool in IPM Programme
}

\author{
N.P. Rathod*, M.G. Savalia and H.G. Kanara \\ ${ }^{1}$ Polytechnic in Agriculture, Dalkhaniya Road, Junagadh Agriculture University, \\ Dhari-365640 dis-Amreli, Gujarat, India \\ ${ }^{2}$ Grass Land research station, Bagasara Road, Junagadh Agriculture University, \\ Dhari-365640 dis-Amreli, Gujarat, India \\ *Corresponding author
}

\section{A B S T R A C T}

In the recent era of modern insecticides, indiscriminate use of pesticides according to calendar base schedules not only results in unnecessary expenditure but it also creates many secondary problems like pesticides resistance, disruption of agro-ecosystem and

Keywords

ETL

Tool in IPM

Programme,

Economic threshold

Article Info

Accepted:

20 January 2018

Available Online:

10 February 2018 environmental pollution. Therefor use of Economic threshold level in which the population density at which control measures should be under taken to prevent an increasing pest population from to reaching the economic injury level.The main importance is for decision making on scheduling of control and control methods by which when control methods are applied to establish the optimal amount of control this can be used to minimize risk of economic damage and environmental hazards. There are three ways of determining the economic threshold level in this we are determine the pest density at which some control should be exerted to prevent a pest population from increasing further and causing economic loss e.g. Bean leaf beetles in soybeans when defoliation reaches 30 percent (before bloom) and there are 5 or more beetles per foot of row.In the biological control use of parasites and predators for the control of insect pest is also dependent upon the realistic economic injury levels.We candetermine ETL for the different crop pest. So economic threshold level is an important tool in IPM programme and by using in management of insect-pest. We are estimating the cost: benefit ratio of different treatments used in the control operation.

\section{Introduction}

Since the advent of the era of modern synthetic insecticides, there has been a tendency among many farmers to spray or dust the crops too often just to ensure that they remains free from the attack of the pests. Therefore, indiscriminate use of pesticides according to calendar base schedules not only results in unnecessary expenditure but it also creates many secondary problems like pesticides resistance, disruption of agroecosystem and environmental pollution. Stern et al., (1959) were the first to put forward the concept of economic threshold for the pest control work. They have defined this term and 
its concept as "Economic threshold level: is the population density at which control measures should be under taken to prevent an increasing pest population from to reaching the economic injury level."

\section{Concept of economic threshold}

Chant (1966) thought that action threshold best describes the concept of economic threshold. The action threshold is the level of pest population at which action must to be taken to prevent the population from rising to the level where significant damage will occur. All the organisms are subjected to the physical and biotic pressure of the environment in which the live. These environmental factors, together with the genetic make-up of the species, determine their existence and abundance in any given area.

\section{Importance of economic thresholds in IPM}

The main importance is for decision making on scheduling of control and control methods by which when control methods are applied. To establish the optimal amount of control this can be used to minimize risk of economic damage and environmental hazards.

\section{Determination of economic threshold level}

Smith and Reynolds(1966) Studied and given the three ways of determining the economic threshold level Due to enormous cost and effort involved, economic threshold should first be determined against one or two most important pests which are called the key pests. There are three ways of determining the economic threshold level.

\section{With the help of a regression line}

In these cases correlation is worked out between the pest population and damage caused on the bases of the data collected from a large no of fields. This helps in determining the economic threshold taking in to consideration the cost: benefit analysis of the pest control.

\section{Treated vs untreated field experiments}

In this case pest is controlled at different levels of population with the help of some suitable insecticides, extent of control achieved and the yield obtained are compared and statistically analyzed. Economic threshold is fixed at a level which given maximum return.

\section{By laboratory experiments}

In some cases population of the pests is maintained at different levels under field cases or glass houses. The damage caused is determined and this information is used in fixing the economic threshold. Generally, the ET level is fixed provisionally on the basis of the experience of the crop protection specialists. Is a subsequently reviewed and readjusted with the additional information from the further field observation.

Revision of et otherwise also become necessary since change occur in the farming practices and as new plant varieties will become available e.g. in California experience for the pest many years showed that the long standing treatment level of 4 bollworm larva $/ 100$ plants of the first and second instars per 100 terminals. The larger larvae cause damage but are not included in ET level because they are resistant and can no longer be killed with pesticides available for use on cotton.

\section{Types of IPM economic threshold level}

Watson et al., (1976) reported the concepts involved in the development and use of 
economic thresholds. Given the different types of economic threshold levels. Metcalf et al., (1975) study the characteristics of economic threshold level.

\section{Economic thresholds (action thresholds)}

\section{Definition}

The pest density at which some control should be exerted to prevent a pest population from increasing further and causing economic loss.

\section{Examples}

Bean leaf beetles in soybeans: "When defoliation reaches 30 percent (before bloom) and there are 5 or more beetles per foot of row".

Black cutworms in corn: "apply a post emergence rescue treatment when 3 percent or more of the plants are cut and the larvae are still present.

\section{Damage Thresholds}

\section{Definition}

The maximum damage a crop can sustain without yield loss

Generally used for plant diseases.

Since disease pathogens are too small to be easily seen, counting their numbers is impractical, so an estimate is made of the amount of damage caused by them.

\section{Examples}

Counting diseased leaf petioles for soybean pod and stem blight.

Estimating the percentage of whole plant infection caused by fungal leaf blights in corn

\section{Economic injury thresholds}

\section{Definition}

The lowest pest density at which economic damage occurs.

Where the cost of the control measure is equal to the loss likely to be inflicted by the pest. If pest populations reach this boundary, economic damage will occur. This threshold is above the economic threshold, the economic threshold most be achieved first, before this threshold can be reached.

\section{Example}

Beet army worm on melons: if army worms begin feeding on fruits

\section{Aesthetic thresholds}

\section{Definition}

The level at which a pest causes an undesirable change in the appearance of something, typically ornamental plants.

This threshold can be used by homeowners, in parks and other public areas and can be highly personal to the user or users.

\section{Example}

Box elder bug: a harmless insect, except its tendency to aggregate en masse on the exterior of homes makes people fearful of it.

\section{Degree day models}

\section{Definition}

Models used to predict the emergence of the first generation of an adult pest, typically after winter. These models are based on the time of the year and temperature. 
Use in Hawaii and the Pacific: These Models are not readily usable in these areas due to:

Overlapping generations of pests and no distinct first generations

Fairly uniform temperatures year round

\section{Economic thresholds and biological control}

Van Emden and Williams (1974) the use of parasites and predators for the control of insect pest is also dependent upon the realistic economic injury levels.

Parasites and predators, by their very nature, cannot prevent all damage by a given pest because their relationships with the pest have tended to evolve to the point where both are survive and the host is not reduced to zero.

\section{Determination of ETL for the different crop pest}

Chaturvedi (2007) studied that in late-planted crops the populations and scouting detected more larvae than eggs, and the larval threshold of one larva per plant was commonly exceeded. The egg threshold of two per plant was not exceeded.

Kumar et al., (2008) found that five per cent silver shoot level may be considered as the economic threshold level for Asian rice gall midge population in Coastal Karnataka.

Anjum et al., (2008) reported that at 3\% infestation level chemical control was not economical at 5 percent infestation level economical one so it is the ETL of the rice stems borers.

Patel (1995) studied the economic threshold level of the $H$. armigera in gram were 1.15 , $1.11,1.33$ and 1.04 larvae/m row length for the all the respective insecticides.
Dodia et al., (1996) observed that control measures for the WBPH should be initiated at the population of 5-10 WBPH/hill.

Ahuja (1999) studied that the seed yield in case of plot having 15, 20, 25 and more than $25 \%$ plant damage is significantly lower than the plot having the $10 \%$ plant damage.

Singh et al., (2003) founded that the ETL of pest is consider at less than 1 larva/plant, where the EIL is 1 larva/plant.

Zahid et al., (2008) reported that control measures should be initiated when the $M$. vitrata larval population reaches one larva per $m$ row length in mungbean plants in order to prevent the population in reaching economic injury levels.

Raghvani (1991) studied the economic threshold level of the L. erysimi in mustard were $7.75,6.47,13.42,6.76,11.27$ and 9.81 aphid/twig for the all the respective insecticides.

Abhilash and Patil (2008) reported the EIL of 1.16 larvae/plant of $C$. ptychora in soybean.

Economic threshold level is an important tool in IPM programme and by using in management of insect-pest. We are estimating the cost: benefit ratio of different treatments used in the control operation. As well as it determine the treatment levels when the control operation should be undertaken to prevent an increasing pest population from to reaching the economic injury level.

So by this we are reducing the indiscriminate use of pesticides according to date-bound schedules not only the results in unnecessary expenditure but it also creates many secondary problems including pesticides resistance, disruption of agro-ecosystem and environmental pollution. 


\section{References}

Abhilash, C. and Patil, R.H (2008). Karnataka J. Agric. Sci.21 (3):446-447.

Ahuja, D.B.(1999). Indian Journal Agricultral Sciences. 69(1):65-66.

Anjum S.; Jalil, A.; Muhammad. A. and M. Majid (2008). Pak. Entomol. 30(2):175178.

Chant, D.A. (1966). Nat. Acad, Sci. Nat. Res. Council, publication.1402:194-218.

Chaturvedi. I.K.(2007). Electronic J. Agri.Uni. 10(2):234-241.

Dodia, J.F.: Patel, M.C.; Patel, M.H.; Korat, D.M. And Mehta, K.G. (1996). GAU Res. J. 22(1):61-66.

Kumar, L.V.; Chakravarthy. A. K. and N. E. Thyagaraj (2008). Current Biotica 2(2): 146-152.

Metcalf, R.L. and Luckmann, W. (1975). Introduction to IPM. John Wiley \& Sons, NY. 587 pp.

Patel, A.J.(1995). GAU Res.J. 20(1): 88-92.
Raghvani, K.L.(1991) Ph. D. Thesis submitted to RAU, Udaipur.

Singh K.J.; Nema, K.K. and Tripathi, A.K. (2003). Indian J. Plant Protection.31(2):103-104.

Smith, R.F. and Reynolds, H.T. (1966). FAO symp. Integrated pest control 1:1117.rome.

Stern, V.M.; Smith, R.F; Van Den Bosch And Hagen, K.S (1959).the integration of chemical and biological control of the spotted alfalfa aphid Hilgardia 29:71101.

Van Emden and Williams (1974). Ann. Rev. Ento. 5:243-264.

Watson, T.F., Moore, L. and Ware, G. W. (1976). W. H. Freeman and Co., San Francisco. 196 pp.

Zahid, M.A.; Islam, M.M.; and Rumana, B. (2008). Bangladesh J. Agril. Res. 33(3): $555-563$.

\section{How to cite this article:}

Rathod, N.P., M.G. Savalia and Kanara, H.G. 2018. A Review: ETL-As a Tool in IPM Programme. Int.J.Curr.Microbiol.App.Sci. 7(02): 2327-2331. doi: https://doi.org/10.20546/ijcmas.2018.702.282 